\title{
Recognizing Discourse Markers as One of the Essential Components for Assisting Students in Acquiring Natural English Communication
}

\author{
Syafitri Ramadhani \\ English Department \\ Universitas Negeri Padang \\ Padang, Indonesia \\ syarasyafitri25@gmail.com
}

\begin{abstract}
As can be seen today, English has been used in most countries in the world. However, not many of the countries use English as their first or second language including Indonesia. The countries still use English as their foreign language in which the language is not spoken in daily communication. It causes English in the countries is not used naturally. It can be seen vividly in English learning process in Indonesia. Many students do not really use English to talk to their teacher also friends. In the classroom, English teachers usually have their students to make up a dialogue. Sometimes, they do not indeed emphasize a context, even ask the students to create the dialogue freely. It often leads the students not to do the dialogue naturally then. One of the good ideas to assist the students in speaking English naturally is by recognizing discourse markers. Discourse markers are markers which can make messages delivered in a conversation developed and coherent. They can be words, phrases, and clauses. They also influence the flow of the conversation. By employing the discourse markers, statements that are uttered are smooth and easy to be grasped by the listeners. Therefore, this paper aims to explain to the readers, especially English teachers that recognizing discourse markers is beneficial for the students to achieve natural English communication.
\end{abstract}

Keywords-Discourse marker; natural English communication

\section{INTRODUCTION}

These days, almost all of countries around the world have been speaking English. Many of the countries have included English as one of the learnt subjects at school started from elementary school. It also occurs in Indonesia today. English has been taught to students twice a week at school. It clearly proves that English is considered as a main subject needed to be studied in Indonesia.

One big obstacle that is faced by many Indonesian students to learn English is the existence of a natural environment in which they may have a lot of chances to speak in English with people around them. As a matter of fact, English in Indonesia is still used as a foreign language. It is not spoken in daily conversation yet. It is just learned and used by the students in English class at school.
Unfortunately, chances the students have in the classroom are not really taken by them. In fact, just a few of the students take their opportunities to use English while they are studying. Hence, it could be one of the reasons why Indonesian students are still difficult to acquire natural English communication, even though they have learned it for several years.

From the phenomena, there is one essential component in English which is overlooked in the learning process. It is named discourse marker (DMs). It is a component which has an important role to create an interaction between speaker and listener in a conversation. discourse markers have a fundamental role in the pragmatic structure of interaction [1]. In other words, by employing the discourse marker, the interaction which occurs between the speaker and listener run better including interactions between teacher and student in the classroom.

Moreover, the discourse marker assists the students to improve their language skills, specifically in speaking. According to Bussman, the use of discourse markers help speakers develop language skills, feel more comfortable about their conversational skills, and allow speakers to collect their thoughts before officially speaking [2]. Thus, recognizing the use of discourse marker in the learning process is useful for the students to acquire and develop their English skills. Indeed, the students are really helped to deliver their messages when they are speaking in English.

In detail, discourse marker is defined as words, phrases or clauses that functions to relate the previous statement to the next statements. It influences the coherence of the statements delivered. Reference [3] explains that the discourse markers mark discourse coherence. In a conversation, a spoken discourse will be produced. When the speaker utters some statements to the listeners by providing the needed discourse markers, the coherence of the discourse is marked by the marker. It also makes the listeners easy to get the intended interpretation of the discourse.

As stated before, if the speaker employs a discourse marker in delivering a statement, the listeners can 
interpret what the speaker say properly. Reference [3] explains that in order to aid hearers in how they should interpret particular contributions within the overall conversation, a speaker might use discourse markers to signal for the benefit of the hearers how various parts of the discourse are intended to be understood as related. In other words, considering the use of discourse marker assists the listeners to interpret the speaker's statements. If it occurs in the classroom in which the student as a speaker delivers his or her messages by including an appropriate discourse marker, the other students can grasp the messages easily.

Based on the explanation before, it is vivid that the discourse marker is necessary to be recognized by the students because of its roles and functions especially for mastering their speaking skills. Since the discourse marker tends to be ruled out in teaching and learning process in the classroom, this paper explains to the readers, especially English teachers and students how important to recognize and consider the discourse marker in their communication is. Mainly for the students, it really helps them to reach natural English communication at least when they talk to their teacher or other students in the classroom.

\section{WHAT IS DISCOURSE MARKER?}

Many of Indonesian English teachers and students do not recognize the terminology of discourse marker, though they ever use words or phrases which belong to the discourse marker. It might occur because they never hear the terminology before or do not exactly know what the discourse marker itself is. Therefore, it is necessary for them to know the definition of the discourse markers. There are many theories and experts have given its definition.

The first definition is given by [4], discourse markers are sequentially dependent elements which bracket units of talk. She states that discourse markers are a linguistic device that speakers use to signal how the upcoming unit of speech or text relates to the current discourse state [4]. It can be stated that an essential component is used to signalize the statements delivered by a speaker named discourse marker.

Furthermore, discourse marker can be defined as an expression employed by the speakers when they talk to the listeners. Reference [5a] explains that discourse marker is an expression that signals the relationship of the basic message to the foregoing discourse. Likewise, discourse markers can be defined as linguistic expressions of varying length which carry pragmatic meaning and can facilitate the discourse [6]. In short, discourse markers are expressions that speakers utilize to lead the listeners to interpret the statements which are being uttered.

Clearly, the discourse marker can be a word, phrase and clause to connect the utterances or sentences delivered. Discourse markers are defined as words and phrases outside of the clause structure which function to link segments of the discourse to one another in ways which reflect choices of monitoring, organization, and management exercised by the speaker [7]. Then, [8] express that incomplete phrases or words in initiating, maintaining, and ending the conversation is called discourse markers. It can be concluded that discourse markers can be defined as words, phrases also clauses that function to connect statements delivered to help the speaker in monitoring, organizing and managing their statements.

In conclusion, the discourse marker is clearly defined as words, phrases, or clauses which function to link the utterances delivered and make them developed and coherent. Moreover, it assists the speaker to monitor, organize and manage their utterances while they are talking. It also leads the listeners to understand the speaker's utterances.

\section{TYPES OF DISCOURSE MARKER}

Discourse marker, in many theories, is divided into several types. The discourse markers are categorized into four types [5b]. The first type is topic change marker. It is defined as a marker which is employed to move one topic to a new topic in the next part. The second type is named contrastive markers. The markers cue that there are two contrast things which is being underlined. In other words, if the previous statement contrasts with the next statement, a contrastive marker is used to emphasize it. The third type is called elaborative markers. The markers cue that the next utterance elaborates the explanations of the previous utterance. The fourth type is entitled as inferential markers. The markers express a conclusion of the utterances explained before. In details, words, phrases or clauses which are classified into each type of discourse marker explained above can be seen in Table 1 as follows:

Table 1. Types of Discourse Markers Categorized by Fraser

\begin{tabular}{|c|l|}
\hline $\begin{array}{c}\text { Types of } \\
\text { Discourse } \\
\text { Marker }\end{array}$ & \multicolumn{1}{c|}{ Examples } \\
\hline $\begin{array}{c}\text { Topic } \\
\text { Mange }\end{array}$ & $\begin{array}{l}\text { back to my original point, before I forget, } \\
\text { incidentally, just to update you, on a different } \\
\text { note, speaking of X, that reminds me, to change to } \\
\text { topic, to return to my point, while I think of it, } \\
\text { with regards to, by the way. }\end{array}$ \\
\hline $\begin{array}{c}\text { Contrastive } \\
\text { Markers }\end{array}$ & $\begin{array}{l}\text { (al)though, but, contrary to this/that, conversely, } \\
\text { despite (doing) this/that, however, in comparison } \\
\text { (with/to this/that), in contrast (with/to this/that), } \\
\text { in spite of } \\
\text { (doing) this/that, instead (of (doing) this/that), } \\
\text { nevertheless, nonetheless, on the contrary, on the } \\
\text { other hand, rather (than (do) this/that), still, } \\
\text { though, whereas, yet. }\end{array}$ \\
\hline Elaborative & $\begin{array}{l}\text { Above all, also, analogously, and, besides, better } \\
\text { yet, by the same token, correspondingly, } \\
\text { equally, for another thing, further(more), in } \\
\text { addition, in any event, } \\
\text { in particular, I mean, likewise, more to the point, } \\
\text { moreover, namely, on top of } \\
\text { it all, or, otherwise, similarly, to cap it all off, too, } \\
\text { well, what is more. }\end{array}$ \\
\hline
\end{tabular}


Table 1. Cont

\begin{tabular}{c|l}
$\begin{array}{c}\text { Inferential } \\
\text { Markers }\end{array}$ & $\begin{array}{l}\text { Accordingly, all things considered, as a (logical) } \\
\text { consequencelconclusion, as a } \\
\text { result, because of this/that, consequently, hence, } \\
\text { in any case, in this/that case, it } \\
\text { can be concluded that, of course, on that } \\
\text { condition, so, then, therefore, thus. }\end{array}$
\end{tabular}

From the table, there are four types of discourse marker differentiated by [5b]. They are topic change markers, contrastive markers, elaborative markers and inferential markers.

Besides, [5b] also mentions several words which are included in the discourse marker, such as after all, because, for this/that reason and since, however, they are not named. Meanwhile, those words and phrases, because, after all, for this/that reason and since, are labeled as causative markers by [9]. It can be stated that there is one more type of discourse marker which is called as causative markers.

Reference [10] also has same types of discourse marker. Yet, they give some other words, phrases or clauses for topic change marker and divide the contrastive markers more detail. Beside incidentally, they also add now as topical change markers. They categorize the use of incidentally, now as transitional markers at discoursal level and point that these conjuncts serve to shift attention to another topic or a temporally related event, with now usually taking a discourse-initial position. For contrastive markers, they classify the markers into four types, such as, reformulatory, replacive, antithetic, and concessive. The next type is elaborative markers which are divided into two types, they are equative conjuncts (equally, likewise, similarly, by the same token) and reinforcing conjuncts (also, moreover, in addition, above all, on top of it all). This set of conjuncts is categorized as the additive which helps to convey the idea of an integral relation. Moreover, they classify a class of common conjuncts as inferential markers (else, otherwise, in other words, in that case) but differentiate a group of resultive markers (so, accordingly, consequently, therefore, as a result). Hence, there are also four types of discourse marker categorized by [10], such as, topic change markers, contrastive markers, elaborative markers and inferential markers which are also employed in spoken language.

Moreover, Stenström composes words, phrases and clauses that are named as interactional signals and discourse markers, such as actually, ah, all right, anyway, God, goodness, gosh, I mean, I see, I think, hmm, no, now, oh, $O K$, please, quite, really, right, sort of, sure, $Q$ tag, that's right, yes/yeah, you know, you see, well [11]. These markers are commonly used in spoken language. In other words, they are employed as discourse markers as a speaker and listeners interact each other in a communication.

From the theories explained before, it can be concluded that types of discourse markers are, topic change markers, contrastive markers, causative markers, elaborative markers, inferential markers and interactional markers. Each type of the marker has various words, phrases or clauses. They can be used by the speakers, in this case, students to speak English naturally. Because of that, it is necessary for the students to identify each type of the discourse marker.

\section{FUNCTIONS OF DISCOURSE MARKER}

After considering the types of discourse marker, of course each type of the marker has its own function. There are two pragmatic functions of discourse marker, namely textual functions and interpersonal functions. In details, textual functions are (1) to initiate discourse, including claiming the attention of the hear (opening frame marker); (2) to close discourse (closing frame marker); (3) to aid the speaker in acquiring or relinquishing the floor (Turn takers (Turn givers)); (4) to serve as a filler or delaying tactic used to sustain discourse or hold the floor (Fillers and Turn keepers); (5) to indicate a new topic or a partial shift in topic (Topic switchers); (6) to denote either new or old information (Information indicators); (7) to mark sequential dependence (sequence/relevance markers); (8) to repair one's own or other's discourse (repair markers) [12].

The second one is interpersonal functions which are (1) subjectively, to express a response or a reaction to the preceding discourse including also back-channel signals of understanding and continued attention while another speaker is having his/her turn (Response/reaction markers and Back-channel signals); (2) interpersonally, to effect cooperation or sharing, including confirming shared assumptions, checking or expressing understanding, requesting confirmation, expressing difference or saving face (politeness) (Confirmation-seekers and Face-savers). Therefore, based on Brinton's explanation, there are two functions of discourse marker, such as textual and interpersonal [12].

Furthermore, [13] classifies a core functional paradigm of discourse markers namely interpersonal, referential, structural, and cognitive category. First, in interpersonal category, discourse markers are used to mark shared knowledge (you know, you see, etc), indicate responses like agreement, confirmation and acknowledgement (ok, alright, I see, etc) in a way to claim understanding, and to mark attitudes of speaker (I think, you know, etc) and help express certainty about propositional meanings (actually, really, etc). Second, in referential category, discourse markers work on a textual level and mark a relationship of verbal activities preceding and following a discourse marker, for instance, because, but, so, and, etc.

Third, in structural category, discourse markers function to signal links and transitions between topics, for instance, signposting opening and closing of topics (now, let's start, etc), indicating sequential relationship (first, second, next, etc), and marking topic shifts (now, how about, etc). Moreover, in this category, discourse markers are used to mark continuation of the current topic (yeah, 
and, etc), to summarize opinions (so), to regain control over the talk, or to hold the floor. Fourth, in cognitive category, discourse markers are used to denote the thinking process (well, I think, etc), to reformulate or making self-repair (I mean, in other words, etc), to elaborate (like, I mean), to denote hesitation (well, sort of), and to assess the listener's knowledge about the utterances (you know) [13]. In short, the functions of discourse marker are divided into four categories, such as, interpersonal, referential, structural and cognitive.

Besides, [14] reveals that organizing and monitoring are the functions of discourse marker. The first function is organizing. They are (1) open and close: discourse markers often appear in opening and closing a conversation and in opening, re-opening, closing or temporarily closing a topic(e.g. so, (all) right, now, well, anyway, etc); (2) sequence: discourse markers often organize the sequence of an activity or the sequence of operating or making something(e.g. and, and then, finally, first (of all), for a start, going back to, in general, in the first place, next, to sum up, etc); (3) topic boundary: discourse markers are employed to separate one topic to another (e.g $O K$, so, yeah, and, right, anyway); (4) focus: discourse markers are to focus the attention of the listener on something that is of high importance(e.g. hey, listen, look, oh, well, anyway, so). From the first function explained above, it can be revealed that the discourse marker uses to open and close a conversation and a topic; to arrange the procedure of an activity or making something into a good order; to separate the previous topic with the new one; and to help the listeners to focus on the topic being discussed.

The second function is monitoring. They are (1) reformulate: discourse markers are to change the wording in such a way that it better fits the context of interaction or speakers' intentions(e.g. as I was saying, I mean, in a manner of speaking, in other words, to put it in another way, well, etc); (2) shared knowledge: the speakers use discourse markers to check the common knowledge they discuss (e.g. you see, see, you know); (3) responding: discourse makers are utilized to give responses from the statement given (e.g. right, I see, good, great, fine, OK) [14]. From the two functions, it can be stated that the discourse markers employed by speakers can function to organize and monitor the messages which are being uttered.

Based on the explanation, it can be concluded that there are several functions of discourse marker. First is to open and close a discourse. Second, it is employed to start or move to a new topic. Third, it is to express any kinds of response. Fourth, it is to assist listeners in interpreting the speaker's utterances. Fifth, it is to connect one sentence with the previous one. Sixth, it is used to arrange a procedure of an activity. Seventh, it is to elaborate an idea which is being explained. Finally, it influences the interaction occurs between speaker and listener which can bring natural communication in their conversation.

\section{WHAT MAKES DISCOURSE MARKER IMPORTANT TO BE RECOGNIZED TO EFL STUDENTS}

As explained before, it can be revealed clearly that discourse marker is a useful component which should be regarded in teaching and learning English in the classroom. It is because the marker brings any communicative purposes in a conversation or dialogue occurs between speaker and listener. It is explained by [15], discourse marker might have varied communicative functions simultaneously, for instance, informs, elaborations of various kinds, suggestions, warnings, disagreements, etc. It means that when a speaker wants to elaborate his or her previous statement, they can use furthermore, moreover, also, in addition, etc. Those words give a signal to the listeners that the speaker is elaborating his or her utterances before. Those words are included in elaborative marker. Therefore, by recognizing this type of the marker, the students can explain their statements more detail and expressively.

Besides, if the students want to show that there are two contrast things, they may use but, however, yet, in contrast, etc. Those words and phrases belong to contrastive markers as stated by [5b]. By having the students to identify this type of the marker, the students will be more helpful in telling contrary things. It, of course, assists other students or the teacher to interpret what the student as the speaker means exactly.

Furthermore, it is also for other types of discourse marker which have been explained in the previous sub topic, namely causative marker which is used to express a reason or cause (because, since, etc), inferential marker which functions to conclude a statement or an explanation (in conclusion, therefore, as a result, it can be stated that, etc), topic change marker which is to signal or move to a new topic (by the way, let's come to..., back to my original point, etc), and interactional marker that is to give interactional signal and affect the interaction between speaker and listener (well, you know, I mean, etc). In other words, identifying those types of discourse marker to the students indeed can help them to communicate in English naturally. It is strengthened by [8], who say using discourse markers will help the system's utterances seem more natural to the user. Hence, the students are able to acquire natural English communication when they consider and employ the discourse marker in their communication.

Specifically, [16] concludes that discourse markers are employed to preserve and reach conversational continuity and seen as response signals and essentially interactive to express the relation or relevance of an utterance to the preceding utterance or to the context. In more detail, she emphasizes that the discourse markers are special linguistic materials through which the speakers stop into a text to make their presence felt in the text, to give guidance to an audience as to how the text is organized, what processes are being used to produce it, and what the speaker's intentions and attitudes are regarding the subject matter, the readers, and their text in which the markers can be words, phrases or clauses. From the explanation, it is 
obvious that the discourse marker is really essential to be identified to the students since they have many roles and functions to assist the students in acquiring natural English communication easily.

\section{CONCLUSION}

Discourse marker is defined as a marker of a discourse that is produced by a speaker. It has various functions and roles in delivering utterances in a communication. First, it is used to open and close a discourse. Second, it is employed to elaborate previous explanation. Third, it is to express various attitudes of the speaker, like telling contrary things, opinions, disagreements, etc. Fourth, it is useful to lead and assist the listeners in interpreting the speaker's statement correctly. Therefore, it of course influences the interaction occurs between the speaker and the listeners. By considering the essential functions and roles the discourse markers have, it is suggested to English teachers to familiarize the markers to their students. If the students are accustomed to employing the markers especially when they speak English in the learning process, they may get bigger opportunities to acquire natural English communication. In conclusion, recognizing and considering the use of discourse markers can assist the students to use English naturally in their communication.

\section{References}

[1] Trillo, J.R. "The Pragmatic Fossilization of Discourse Markers in Non-Native Speakers of English". Journal of Pragmatics 34, 769784, 2002.

[2] Sadeghi, Bahador and Yarandi, Reza Ramezan. "Analytical Study on the Relationship between Discourse Markers and Speaking Fluency of Iranian EFL Students." International Journal of Linguistics and Communication. Vol.2, No.2, pp.101-123, 2014.

[3] Lenk, U. "Discourse markers and global coherence in conversation." Journal of Pragmatic 30. Augsburg: Germany. http://www.corpus4u.org/forum/upload/forum/2005072402443553.pd f. 1998. Retrieved on January $10^{\text {th }} 2014$
[4] Schiffrin, D. Discourse Markers. Cambridge: Cambridge University Press, 1987.

[5] Fraser, B. "Pragmatic Markers". Pragmatics 6:2 167190.International Pragmatics Association. 1996a

_ "What are discourse markers?". Journal of Pragmatics. $\overline{\text { Boston }} \quad$ University: Boston.http://www.gloriacappelli.it/wpcontent/uploads/2009/05/dm.pdf. 1999b. Retrieved on January $10^{\text {th }}$ 2014.

[6] Ismail, Hind. M. "Discourse Markers in Political Speeches: Forms and Functions." J. of College of Education for Women, Vol. 23 (4), 2012.

[7] O'Keeffe, A., McCarthy, M., and Carter, R. From Corpus to Classroom: Language Use and Language Teaching. Cambridge: Cambridge University Press, 2007.

[8] Sadeghi, Bahador and Heidaryan, Hooshyar. "The Effect of Teaching Pragmatic Discourse Markers on EFL Learners' Listening Comprehension". English Linguistics Research, Vol.1, No.2, 2012.

[9] Wei, M. A Comparative Study of the Oral Proficiency of Chinese Learners of English: A Discourse Marker Perspective. Dissertation. http://digital.library.okstate.edu/etd/Wei_okstate_0664D_10238.pdf. 2009. Retrieved on May $7^{\text {th }}, 2014$.

[10] Quirk. R., Svartvik. J., Leech. G., Greenbaum. S. A Comprehensive Grammar of the English Language. London: Longman, 1985.

[11] Jönsson, H. The use of the Discourse Markers kind of and sort of in London Teenage Conversation. http://lup.lub.lu.se/luur/download?func $=$ downloadFile\&recordOId $=3$ 878906\&fileOId $=3878908.2013$. Retrieved on January $10^{\text {th }} 2014$.

[12] Brinton, L. Pragmatic markers in English, Grammaticalization and Discourse Functions.Berlin/New York: Mouton de Gruyter, 1996. Google Book. Web. $21^{\text {st }}$ April 2017.

[13] Fung, L.P. The Use and Teaching of Discourse Markers in Hong Kong - Students' Production and Teachers' Perspectives. Thesis: University of Nottingham. Volume 1 July 2003. http://etheses.nottingham.ac.uk/1437/1/397635_VOL1.pdf. Retrieved on January $10^{\text {th }} 2014$

[14] Komar, S. The Interface between Intonation and Function of Discourse Markers in English. Volume IV/1-2. Slovenia, 2007. Retrieved on January $10^{\text {th }} 2014$.

[15] Pethukova, Volha and Bunt, Harry. "Towards a Multidimensional Semantics of Discourse Markers in Spoken Dialogue." Proceedings of the 8th International Conference on Computational Semantics, pages 157-168, Tilburg, January 2009. c 2009 International Conference on Computational Semantics.

[16] Sun, Wei. "The Importance of Discourse Markers in English Learning and Teaching." Theory and Practice in Language Studies, Vol. 3, No. 11, pp. 2136-2140, November 2013. 